\title{
Effect of Wingate-based high intensity interval training on aerobic and anaerobic performance of kick boxers
}

\author{
Akgül M.S. ${ }^{\mathrm{ABCDE}}$ \\ Kastamonu University School of Physical Education and Sports, Kastamonu, Turkey
}

Authors' Contribution: A - Study design; B - Data collection; C - Statistical analysis; D - Manuscript Preparation; E-Funds Collection.

\begin{abstract}
Purpose: $\quad$ The aim of this study was to investigate the effects of two-week high intensity interval training (HIIT) on aerobic and anaerobic performance of kick boxers.

Material: $\quad 24$ male kick boxers (age $19.39 \pm 0.72$ y, body mass $74.14 \pm 6.22 \mathrm{~kg}$, height $177.95 \pm 5.29 \mathrm{~cm}$ ) volunteered for the study. Participants were randomly divided into two groups: experimental and control. As well as routine training program, experimental group carried out Wingate-based HIIT 3 times per week for two weeks. Wingate protocol was as follow: 4 repetitions with 4 mins recovery (4X30sn all-out effort) during the first week, 5 repetitions with 4 mins recovery ( $5 \times 30$ sn all-out effort) during the second week. In order to determine aerobic capacity, $20 \mathrm{~m}$ shuttle run test was used while Wingate anaerobic test was used to determine anaerobic performance. Descriptive statistic was used to demonstrate mean values and standard deviation of the variables. Non-parametric Mann Whitney-U test was used to show the differences between groups. Wilcoxon Signed Rank Test was used to compare intra-groups results from pre and post-test applications.

Results: $\quad$ There was no significant difference between groups during pre-test measurements There was significant difference in PP, MP in experimental group compared to control during the post-test measurements. There was no difference in body mass, body fat (\%) and predicted $\mathrm{VO}_{2 \max }$ in both groups between measurements.

Conclusions: According to intra and inter-group results, it can be concluded that two-week Wingate-based HIIT can be used to improve aerobic and anaerobic performances of kick boxers.

Keywords: aerobic performance, anaerobic performance, high intensity interval training, kick box.
\end{abstract}

\section{Introduction}

Kick box is a combat sport which derives from karate, thai box and west box and mainly depends on kick and punch to defend oneself. A kick box match comprised of 3 rounds and each round lasts 2 minutes. This sport requires not only speed and technical ability but also high power and endurance $[1,2]$. Kick box arouses curiosity around the world as it is thought to be effective way to defend oneself, increase muscle power and keep the body fit.

Energy mechanisms should be taken into account when kick box trainings are planned. Kick box, characterized by short-term high intensity actions, involves both aerobic and anaerobic energy systems. It is stated that energy system contribution to kick box is $70-80 \%$ anaerobic and $20-30 \%$ aerobic [3]. During a kick box match, more than $50 \%$ of ATP is provided by aerobic metabolism [4]. Therefore, it is very important to have a high level of aerobic and anaerobic capacity for kick boxers in order to maintain high intensity efforts and enhance recovery between matches.

It is advised that energy systems can be developed with different training methods such as long-term and submaximal loads for aerobic performance, 3-8 seconds maximum loads for alactic anaerobic energy system and 30-90 seconds submaximal loads for lactic anaerobic system [5].

High intensity interval trainings have stood out recently in terms of enhancing both aerobic and anaerobic

\footnotetext{
(c) Akgül M.S., 2019

doi:10.15561/20755279.2019.0401
}

capacities. This method not only lead to fast adaptation but also shorten the training duration $[6,7]$. There are studies that suggest that 6 HIIT for 2 weeks significantly improved aerobic and anaerobic capacities and metabolic functions [8,9]. This method pays more attention as it shortens the duration of training, enhance both aerobic and anaerobic energy systems, metabolic functions and physical performance when compared to traditional aerobic training programs $[10,11]$. When researchers examined how HIIT was so effective, they found that HIIT affects PGC-1 $\alpha$ (Peroxisome proliferatoractivated receptor gamma coactivator 1-alpha) receptor activation. The more active this receptor is, the more ATP is produced. Moreover, when activation of PGC-1 $\alpha$ increases, the effect of MRNA in the mitochondria increases and thus the duration of mitochondrial adaptation shortens. It is known that activation of this receptor is directly related to intensity of training. HIIT method stimulated this receptor more than traditional endurance trainings. HIIT application was reported to increase the activation of this receptor and thus more energy is produced, which improves maximal activity level by improving muscle oxidation capacity [12].

In addition, it is well-known that other physiological variables should be taken into account when HIIT is used as a training method. These physiological variables are load intensity, duration, recovery duration and content, exercise method, repetition number, set number and duration and content between sets. It has been reported that change in any of these variables may affect acute and chronic physiological answers to training [13]. 
As a result, the aim of this study was to investigate effects of Wingate-based HIIT on aerobic and anaerobic performances of kick boxers.

\section{Material and Method}

\section{Participants}

Twenty-three male kick boxer (age $19.39 \pm 0.72 \mathrm{y}$, body mass $74.14 \pm 6.22 \mathrm{~kg}$, height $177.95 \pm 5.29 \mathrm{~cm}$ ) voluntarily participated in this study. Participants were informed about the study in detail. All participants were told to refrain from strenuous training, food consumption 2 hours before the experiment, not to change their food habits and consume alcohol.

\section{Study design}

Experimental study design was used. 24 male kick box athletes who regularly trained voluntarily participated in this study. They were randomly divided into two groups: experimental and control. As well as their training routine, experimental group carried out Wingate-based HIIT 3 times per week with 1 day intervals for two weeks. Each training session involved a $10 \mathrm{~min}$ warm-up followed by a HIT program consisting of 4-5x30 s all-out sprints with a 4 min recovery. A 5 min cool down period was then performed. Body fat percentages, aerobic and anaerobic performances of the athletes were evaluated before and after the study. Pre and post tests were carried out 72 hours before and 48 hours after the training, respectively. All participant followed the same diet throughout the study.

\section{Study protocol}

Height, body mass index (BMI), body fat weight, body fat percentage (BFP), aerobic capacity (VO2 $\max$ ), anaerobic capacity, were measured before and after the training. To find the aerobic strength of the subjects, 20m shuttle run test was applied. All-out 30s WanT was applied to determine anaerobic performance of the athletes. Height was measured with a stadiometer (Holtain, England) and body mass was measured with Jowan Segmental Body Composition Analyzer (Korea) to the nearest $100 \mathrm{gr}$.

High Intensity Interval Training Program

As well as their training routine, experimental group carried out Wingate-based HIIT with a resistance equal to $\% 7.5$ of body weight 3 times per week for two weeks. Athletes carried out four HIIT (4X30s) during the first week and 5 repetition (5X30s) during the second week.

Control Group Training Program

Control group practiced typical kickbox training for 3 days with 1 day intervals for two weeks. During the first and second weeks of the training plan a and plan $b$ were performed, respectively. Athletes used all the protective materials that are used during the competition.

Plan a: After 20 minutes of warm-up, athletes performed 5 different technique combinations specific to kickbox competitions for 2 minutes with 1 min intervals. Then, athletes performed 3 different games specific to kickbox competition in order to improve distance control for 2 minutes. Lastly, athletes were paired and carried out 3 round simulated kickbox fight.

Plan b: athletes performed the same program as the first week with increased number of repetitions and content of the techniques. Following a 20 min warm-up, athletes applied 7 different combinations of attack and defense techniques. Combinations lasted 2 min with 1 min intervals. Then, 5 X 2 min imaginary workout was carried out with $1 \mathrm{~min}$ intervals. At last, athletes were paired and carried out 3 round simulated kickbox fight.

\section{Statistical Analysis}

Descriptive statistic test was used to show mean and standard deviation of the variables. The differences obtained from two groups were evaluated inter and intragroup. Mann Whitney-U Test was used to determine the differences between two groups. Wicoxon Signed Rank Test was used to determine intra-group differences. Statistical analysis was carried out with SPSS 22 and p value was set at $\mathrm{p}<0.05$.

\section{Results}

Table 1 presents anthropometric profile of the athletes.

Table 2 presents body mass, body fat percentage, Peak Power (W/kg), Mean Power (W/kg), Minimum Power $(\mathrm{W} / \mathrm{kg})$ and predicted $\mathrm{VO}_{2 \max }$ of the kick box athletes.

When the pre-test results presented by both groups were compared, there was no difference $(\mathrm{p}>0.05)$. Accordingly, differences between groups are as follow: body mass $(z=-0.291, p=0.771)$, body fat percentages $(Z=-0.355, p=0.722)$, Peak Power $(Z=-1.743, p=0.081)$, Mean Power $(Z=-1.906, p=0.057)$, Minimum Power $(Z=$ $-0.775, \mathrm{p}=0.438)$, and predicted $\mathrm{VO}_{2 \max }(\mathrm{Z}=0.065, \mathrm{p}=$ 0.945). Nevertheless, significant differences were found between both groups in PP, MP $(\mathrm{p}<0.05)$ after 2 weeks of HIIT while there was no difference in body mass, body fat percentage and predicted $\mathrm{VO}_{2 \max }$. Accordingly, differences between groups are as follow: body mass $(Z=$ $-0.071, p=0.776)$, body fat percentage $(Z=-0.797, p=$ $0.426)$, Peak Power $(Z=-3.22, p=0.001 *)$, Mean Power $\left(\mathrm{Z}=-2.68, \mathrm{p}=0.008^{*}\right)$, Minimum power $(\mathrm{Z}=-2.00, \mathrm{p}=$ $\left.0.045^{*}\right)$, estimated $\mathrm{VO}_{2 \max }(\mathrm{Z}=-1,03, \mathrm{p}=0.302)$.

Table 1. Anthropometric profile of kick boxers

\begin{tabular}{ll}
\hline Variable $(\mathbf{n}=\mathbf{2 4})$ & Mean \pm SD \\
\hline Age $(\mathrm{y})$ & $19.39 \pm 0.72$ \\
Height $(\mathrm{cm})$ & $177.95 \pm 5.29$ \\
Weight $(\mathrm{kg})$ & $74.14 \pm 6.22$ \\
Body fat percentage (\%) & $11.96 \pm 3.27$ \\
\hline
\end{tabular}


Table 2. Pre-test and post-test analysis results of the experimental and control groups

\begin{tabular}{|c|c|c|c|c|c|c|c|c|c|c|}
\hline \multirow{2}{*}{ Variables } & \multicolumn{5}{|c|}{ EXPERIMENTAL } & \multicolumn{5}{|c|}{ CONTROL } \\
\hline & Pretest & Std. & Posttest & Std & $\mathbf{P}$ & Pretest & Std. & Posttest & Std. & $\mathbf{P}$ \\
\hline $\begin{array}{l}\text { Weight } \\
\text { (kg) }\end{array}$ & 74.52 & 6.35 & 74.66 & 6.77 & 0.774 & 73.43 & 6.32 & 74.52 & 7.27 & 0.070 \\
\hline Body Fat (\%) & 12.46 & 2.58 & 11.36 & 3.58 & 0.581 & 11.03 & 4.32 & 11.78 & 3.97 & 0.061 \\
\hline $\begin{array}{l}\text { Peak Power } \\
(\mathrm{W} / \mathrm{kg})\end{array}$ & 11.47 & 0.85 & 12.44 & 0.97 & $0.001^{*}$ & 10.69 & 0.91 & 10.84 & 0.68 & 0.289 \\
\hline $\begin{array}{l}\text { Mean Power } \\
(\mathrm{W} / \mathrm{kg})\end{array}$ & 8.26 & 0.46 & 8.54 & 0.65 & $0.013^{*}$ & 7.84 & 0.41 & 7.81 & 0.34 & 0.998 \\
\hline $\begin{array}{l}\text { Minimum } \\
\text { Power (W/kg) }\end{array}$ & 4.45 & 0.83 & 5.22 & 0.72 & 0.118 & 3.85 & 1.34 & 4.66 & 0.45 & 0.727 \\
\hline $\begin{array}{l}\mathrm{VO}_{2 \max }(\mathrm{ml} / \mathrm{kg} / \\
\min )\end{array}$ & 46.16 & 3.10 & 49.49 & 2.95 & $0.006^{*}$ & 46.15 & 4.21 & 47.57 & 0.45 & 0.625 \\
\hline
\end{tabular}

\section{Discussion}

The HIIT program was created as a strategy for shortens the duration of the exercise and increase performance as well as leading to fast metabolic adaptation. It helps to improve both performance in short term even 5 sessions [14]. Previous studies highlighted that the application of HIIT draws attention as improves both aerobic and anaerobic performances in literature $[6,10,11]$. Furthermore, literature suggested that HIIT have positive effects on athletes' performance and present positive adaptation [6]. In our knowledge 3 times for 2 weeks of HIIT was enough to improve exercise capacity [15]. In light of this information's we evaluated the effect of 2-week HIIT program on kick boxers performance.

The main finding of this study was that 2-week HIIT significantly improved anaerobic performance of kick boxers. Anaerobic power has been considered important to support high-intensity actions during combat sports and anaerobic power and capacity are considered key elements for successful performance in combat sports [16]. Laursan et al. stated that 5 times HIIT significantly enhanced $\mathrm{VO}_{2 \mathrm{~m}}$ and anaerobic performance outputs of elite cyclists [14]. Another study by Tom et al. investigated effects of HIIT on cardiovascular functions and aerobic-based exercise capacity of sedentary and first grade obese people and found that HIIT increased cardiovascular functions and aerobic-based exercise capacity [17]. Akgül et al. applied the same protocol on physically active women and found that it led to percentage changes in $\mathrm{VO}_{2 \max }(4.44 \%)$, VO2peak (8.09\%), TTE (7.4\%) [6]. Barker et al. stated that two-week Wingate-based HIIT applied to physically active men improved aerobic capacity [18]. Our results support previous findings. The percentage changes in the experimental group were as follow: PP $(8,45 \%)$, MP $(3,38 \%) \mathrm{VO}_{2 \max }(7,21 \%)$. Talanian et al. suggested $13 \%$ of improvement in $\mathrm{VO}_{2 \max }$ in women after 7 sessions of HIIT for two weeks [19]. Bayati et al. stated an improvement of $10,3 \%$ and 9,7 for $\mathrm{PP}$ and $\mathrm{VO}_{2 \max }$, respectively in their study where they applied 4 weeks of HIIT on active individuals [20].

When intragroup changes are taken into consideration, there was no difference between groups in our study, there was a significant difference when pre and post-test results of the experimental group were compared $(p=0.006)$. In this sense, our findings are in accordance with the findings in the literature [21]. Barker et al. demonstrate that meaningful changes in health outcomes are possible in healthy adolescent boys after just six sessions of highintensity interval training over a 2 -week period [22].

Studies state that energy system contribution to kick box is $70-80 \%$ anaerobic and $20-30 \%$ aerobic [4]. Accordingly, it can be suggested that HIIT is a beneficial method to improve anaerobic capacities of kick boxers as it lead to this improvement only for two weeks. As no other study has been carried out with kick boxers in terms of effects of HIIT on performance, this study can be used by coaches to improve their athletes' performances. Many studies were carried out with sedentary or physically active people but a sport specific study about effects of HIIT is limited.

\section{Conclusions}

As there is not enough information about adaptation duration it can be advised that HIIT protocol can be applied to other sports. More studies can be carried out to determine the duration of adaptation period or differences between genders and different ages as they can contribute to literature. Moreover, physiological and physical answers by elite and non-elite athletes to HIIT can also be studied as it can help design training programs. As a result, it can be inferred that two-week and 6 sessions HIIT is an effective way to improve aerobic and anaerobic performance of kick boxers.

\section{Conflict of interest}

There were no conflicts of interest. 


\section{References}

1. Gartland S, Malik M, Lovell ME. Injury and injury rates in Muay Thai kickboxing. Br J Sports Med 2001;35:308- 313. https://doi.org/10.1136/bjsm.35.5.308

2. Zazryn TR, Finch CF, McCrory PA. 16 year study of injuries to professional kick boxers in the state of Victoria, Australia. Br J Sports Med, 2003;37:448- 451. https://doi.org/10.1136/bjsm.37.5.448

3. Ghosh AK, Goswami A, Ahuja A. Heart rate and blood lactate response in amateur competitive boxing. Indian Journal of Medical Research, 1995; 102:179-183.

4. Plowman SA, Smith DL. Exercise physiology for health, fitness, and performance. 2nd ed, Benjamin Cummings publishing house; 2008.

5. Ziyagil MA, Şampiyon kikboksörün antrenman ilkeleri. Türkiye Kick Boks Federasyonu Spor Bilimleri Dergisi, 2008;1(1):13-22.

6. Akgül MŞ, Gürses VV, Karabıyık H, Koz M. The influence of 2 weeks of low- volume high intensity interval training on aerobic indices in women. International Journal of Science Culture and Sport, 2016;4(1):298- 305. https://doi.org/10.14486/IntJSCS558

7. Buchheit M, Laursen PB. High-intensity interval training, solutions to the programming puzzle: Part I: Sports Med, 2013; 43(5): 313- 338. https://doi.org/10.1007/s40279-013-0029-x

8. Alan RB, Josephine D, Aaron S, Bert B, Craig AW. The influence of 2 weeks of low-volume high intensity interval training on healtj outcomes in adolescent boys. Journal of Sport Sciences, 2014; 32(8):757- 765. https://doi.org/10.1080/02640414.2013.853132

9. Babraj JA, Vollaard NB, Keast C, Guppy FM, Cottrell G, Timmons JA. Extremely short duration high intensity interval training substantially improves insulin action in young healthy males. BMC Endocrine Disorders [Internet]. 2009 Dec [cited 2019 Jul 14];9(1). https://doi.org/10.1186/1472-6823-9-3

10.Bayati M, Farzad B, Gharakhnlou R, Alınejad HA. A practical model of low-volume high-intensity interval training induces performance and metabolic adaptations that resemble 'all-out' sprint interval training. Journal of Sports Science and Medicine, 2011; 10:571-576.

11. Greeley SJ, Martinez N, Campbell BI. The Impact of HighIntensity Interval Training on Metabolic Syndrome. Strength and Conditioning Journal. 2013;35(2):63-5. https://doi. org/10.1519/SSC.0b013e31827764da

12.Little JP. A practical model of low- wolume highintensity interval training induces mitochondrial biogenesis in human skeletal muscle:potential mechanisms. J Physiol, 2010; 588: 1011-1022. https://doi.org/10.1113/jphysiol.2009.181743
13.Gibala MJ, Mc Gee SL. Physiological adaptations to low-volume, high-intensity interval training in health and disease. $J$ Physiol, 2012; 59:1077-1084. https://doi.org/10.1113/jphysiol.2011.224725

14.Laursen PB, Blanchard MA, Jenkins DG. Acute high-intensity interval training improves Tvent and peak power output in highly-trained males. Can J Appl Physiol, 2002; 27:336-348. https://doi.org/10.1139/h02-019

15.Jacobs RA, Flück D, Bonne TC, Bürgi S, Christensen PM, Toigo M, et al. Improvements in exercise performance with high-intensity interval training coincide with an increase in skeletal muscle mitochondrial content and function. Journal of Applied Physiology. 2013;115(6):785-93. https://doi.org/10.1152/japplphysiol.00445.2013

16.Franchini E, Dunn E, Takito MY. Reliability and Usefulness of Time-Motion and Physiological Responses in Simulated Judo Matches: Journal of Strength and Conditioning Research. 2018;1:1-11. https://doi.org/10.1519/JSC.0000000000002727

17. Tong TK, Chung PK, Leung RW, Nie J, Lin H, Zheng J. Effects of Non-Wingate-based High-intensity Interval Training on Cardiorespiratory Fitness and Aerobic-based Exercise Capacity in Sedentary Subjects: A Preliminary Study. Journal of Exercise Science \& Fitness. 2011;9(2):75-81. https://doi.org/10.1016/S1728-869X(12)60001-X

18.Alan RB, Josephgine DAY, Aaron S, Bert B, Craggg AW. The influence of 2 weeks of low-volume high intensity interval training on healtj outcomes in adolescent boys. Journal of Sport Sciences. 2014; 32(8):757-765. https://doi.org/10.1080/02640414.2013.853132

19.Talanian JL, Galloway SDR, Heigenhauser GJF, Bonen A, Spriet LL. Two weeks of high-intensity aerobic interval training increases the capacity for fat oxidation during exercise in women. $J$ Appl Physiol. 2000; 102:1439-1447. https://doi.org/10.1152/japplphysiol.01098.2006

20.Bayati M, Farzad B, Gharakhanlou R, Alinejad HA. A practical model of low-volume high-intensity interval training induces performance and metabolic adaptations that resemble 'all-out' sprint interval training. Journal of Sports Science and Medicine. 2011; 10, 571-576.

21.Podrigalo LV, Volodchenko AA, Rovnaya OA, Ruban LA, Sokol KM. Analysis of adaptation potentials of kick boxers' cardio-vascular system. Pedagogics, psychology, medical-biological problems of physical training and sports, 2017;21(4):185-191. https://doi.org/10.15561/18189172.2017.0407

22.Barker AR, Day J, Smith A, Bond B. Williams CA. The influence of 2 weeks of low-volume high intensity interval training on healtj outcomes in adolescent boys. Journal of Sport Sciences. 2014; 32:(8) 757-765. https://doi.org/10.1080/02640414.2013.853132 


\section{Information about the author:}

Akgül M.Ş.; http://orcid.org/0000-0002-9696-6541; msakirakgul@gmail.com; School of Physical Education and Sports, Kastamonu University; 37150 Kastamonu, Turkey.

\section{Cite this article as:}

Akgül MS. Effect of Wingate-based high intensity interval training on aerobic and anaerobic performance of kick boxers. Physical education of students, 2019;23(4):167-171.

https://doi.org/10.15561/20755279.2019.0401

This is an Open Access article distributed under the terms of the Creative Commons Attribution License, which permits unrestricted use, distribution, and reproduction in any medium, provided the original work is properly cited http://creativecommons.org/licenses/by/4.0/deed.en

Received: 22.05.2019

Accepted: 25.06.2019; Published: 28.08.2019 